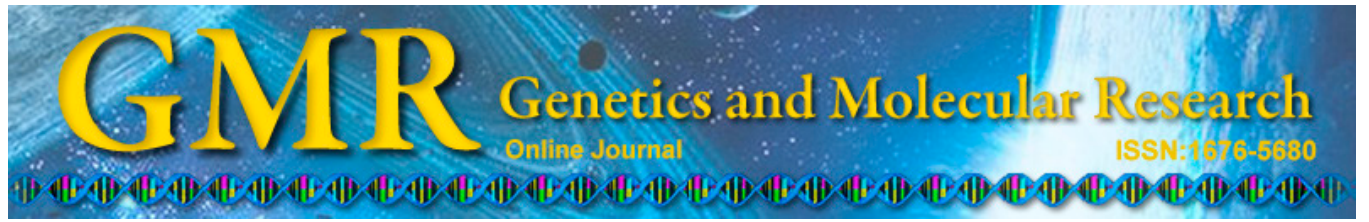

\title{
Effect of bone marrow mesenchymal stem cells on the TGF- $\beta 1 /$ Smad signaling pathway of hepatic stellate
}

\author{
X.E. Sun ${ }^{1}$, X.Q. Zhang ${ }^{2}$ and M.M. Liu ${ }^{3}$ \\ ${ }^{1}$ Department of Infectious Diseases, Affiliated Hospital of Weifang, \\ Medical University, Weifang, Shandong Province, China \\ ${ }^{2}$ Department of Gastroenterology, \\ Affiliated Hospital of Weifang Medical University, Weifang, \\ Shandong Province, China \\ ${ }^{3}$ Department of Emergency, Weifang People's Hospital of Shandong, Weifang, \\ Shandong Province, China \\ Corresponding author: X.Q. Zhang \\ E-mail: zhangxiaoqian 1@163.com \\ Genet. Mol. Res. 14 (3): 8744-8754 (2015) \\ Received December 2, 2014 \\ Accepted April 24, 2015 \\ Published July 31, 2015 \\ DOI http://dx.doi.org/10.4238/2015.July.31.23
}

\begin{abstract}
This study investigated the effect of bone marrow mesenchymal stem cells (BMCs) on the transforming growth factor- $\beta 1$ (TGF- $\beta 1$ )-induced activation of the Smad signaling pathway in rat hepatic stellate cells (HSCs). There were four experimental groups: 1) a blank control group, 2) a TGF- $\beta 1$ treatment group, 3) an MSCcombined group, and 4) an induced MSC-combined group. Isolation and culture of rat liver HSCs in vitro and the proliferation of HSCs in each group were detected by MTT method. The expression of $\alpha$-SMA and the TGF receptors (T $\beta$ RI and II) were determined by immunohistochemical staining of HSCs in all groups, while Smad2/3, Smad4, and Smad7 mRNA expressions were detected by RT-PCR for HSCs in each group. TGF- $\beta 1$ treatment significantly promoted the
\end{abstract}


proliferation of HSCs $(\mathrm{P}<0.01)$; it has different inhibition effects on the proliferation of HSCs in the MSC-combined group and in the induced MSC-combined group $(\mathrm{P}<0.05)$. TGF- $\beta 1$ treatment also enhanced the expression of $\alpha$-SMA as compared to the control group $(\mathrm{P}<0.01)$. Alternatively, when compared with the pure TGF- $\beta 1$ group, the MSCcombined group and the induced MSC-combined group showed lower $\alpha$-SMA expression $(\mathrm{P}<0.05)$. Activation of HSCs induced by TGF- $\beta 1$, $\mathrm{T} \beta R \mathrm{R}$ and T $\beta R I I$ fluorescence was $(+++)$; the fluorescences of T $\beta R I$ and T $\beta$ RII in MSC-combined group and in induced MSC-combined group were $(++)$ and $( \pm \sim+)$, respectively. The expressions of T $\beta R I$ and T $\beta$ RII in activated HSCs induced by TGF- $\beta 1$ were significantly decreased in the MSC-combined group $(\mathrm{P}<0.05)$ and in the induced MSC-combined group $(\mathrm{P}<0.01)$. The expression of HSC Smad $2 / 3$ and Smad4 was reduced in the MSC-combined group $(\mathrm{P}<0.05)$ and in the induced MSC-combined group ( $\mathrm{P}<0.01)$, as compared to the TGF- $\beta 1$ group. However, the expression of Smad7 in HSCs was upregulated in the MSC-combined group $(\mathrm{P}<0.05)$ and in the induced MSCcombined group $(\mathrm{P}<0.01)$. These results indicate that $\mathrm{BMCs}$ can inhibit the activation and proliferation of HSCs by downregulating the expression of T $\beta R I$ and T $\beta$ RII in the cell membrane of HSCs. Moreover, BMCs can upregulate the expression of $\operatorname{Smad} 7$ and downregulate the expression of Smad2/3 and Smad4 in the HSCs induced by TGF- $\beta 1$, which resulted in an inhibition of HSC activation.

Key words: Hepatic stellate cells; TGF- $\beta 1 /$ Smad pathway; Bone marrow mesenchymal stem cells

\section{INTRODUCTION}

The activation of hepatic stellate cells (HSCs) is considered the center link starting process in liver cirrhosis (Sarem et al., 2006). In the variety of pathogenic factor-damaged liver, the static HSCs were activated by the stimulation of hepatocytes, Kupffer cells, liver sinusoidal endothelial cells, inflammatory cells, and other paracrine cytokine activation, it was conserved in muscle fibroblasts (MFBs) and expressed the $\alpha$-smooth muscle actin ( $\alpha$-SMA) marker protein (Cassiman et al., 2002). MFBs and HSCs can be further activated by the cytokines such as transforming growth factor- $\beta 1$ (TGF- $\beta 1$; produced in both a paracrine or endocrine manner), platelet-derived growth factor, hepatocyte growth factor (HGF), and tumor necrosis factor alpha. It synthesizes a large amounts of ECM components, such as collagen I, III, and IV, laminin, fibronectin, and hyaluronic acid (Gressner et al., 2008).

A complex network exists between various cytokines and a variety of signal transduction pathways that participate in the regulation of the pathological process of liver cirrhosis. TGF- $\beta 1$ is considered the strongest profibrotic cytokine and may play an important role in the development of liver fibrosis (Brenner, 2009). Its effects are mainly mediated through the TGF- $\beta 1 /$ Smad signaling pathway (Parsons et al., 2007). Smad proteins are well 
known to be important kinase substrates found in TGF- $\beta$ cells, which act to transmit the extracellular signal of TGF- $\beta$ into the nucleus and regulate the transcription of specific target genes (Lin et al., 2009). The main TGF- $\beta 1$ receptors are T $\beta$ RI and T $\beta$ RII. When TGF- $\beta 1$ binds to the type II receptor, it activates T $\beta$ RII kinase domain. T $\beta$ RI can recognize this complex and bind to it, then, it is activated by T $\beta$ RII phosphorylation kinase. The further phosphorylation of activated T $\beta R I$ was Smad2/3 (R-Smad), the phosphorylation of Smad2/3 and Smad4 (Co-Smad) formed heteromeric oligomers, they translocate into the nucleus and regulate various target genes (Mootsikapun et al., 2003), including collagen types I and III (Massague et al., 2005). Smad7 is an inhibitory Smad (I-Smad) that when bound to a TGF$\beta 1$ receptor or Smad4, blockade Smad2/3 phosphorylation and translocation to the nucleus (Roberts et al., 2003). Therefore, although the TGF- $\beta 1 /$ Smad signaling pathway is involved in the occurrence and development of liver cirrhosis, its signaling members, Smad3 and Smad7, possess different functions.

Numerous studies have demonstrated that the transplantation of bone marrow mesenchymal stem cells (BMCs) can effectively improve liver inflammation and reduce the deposition of ECM and collagen expression, and it also has better effect of anti-hepatic

fibrosis. The purpose of this study was to investigate the effect of BMCs on the TGF- $\beta 1 / \mathrm{Smad}$ signaling pathway within HSCs.

\section{MATERIAL AND METHODS}

\section{Separation and purification of BMCs}

We selected 10 six-week-old male SD rats that weighed between 100-120 g. The BMCs were collected and cultured in L-DMEM containing 10\% fetal bovine serum (FBS) under the conditions of $5 \% \mathrm{CO}_{2}$ at $37^{\circ} \mathrm{C}$. When the cells were $80-90 \%$ confluent, they were cultured with the ratio of $1: 2$; the purified BMCs were acquired after three generations. The purified third-generation BMCs were removed from their culture plates with trypsin, which was added to $10 \%$ FBS L-DMEM. The concentration of BMCs obtained was $2 \times 10^{5}$ cells $/ \mathrm{mL}$.

\section{Induction of MSCs}

MSCs experimental group: MSCs cultured by super-fetal bovine serum. HGF induced group: Added $20 \mathrm{ng} / \mathrm{mL}$ (final concentration) HGF to super-fetal bovine serum to induce the MSCs. They were cultured at the volume fraction of $5 \% \mathrm{CO}_{2}$ and $37^{\circ} \mathrm{C}$, and the liquid was changed every 3 days. MSCs were cultured continuously for 14 days, after which the cells were prepared for further experiments.

\section{Extraction of rat HSCs}

Ninety healthy SD rats, weighing between $180-200$ g, were injected with $10 \%$ chloral hydrate anesthesia (ip). The portal venous system was then intubated and perfused with D-H anks until the liver became soft. At this point, the perfusion was terminated and the liver excised. The liver was digested by dispersing fluid, filtered, and centrifuged. The sample was 
then centrifuged through an $18 \%$ Nycodenz gradient to obtain the high-purity HSCs at the gradient interface. The concentration of HSCs was adjusted to $1 \times 10^{9}$ cells/L in DMEM containing $20 \%$ FBS and then inoculated in a plastic culture flask.

\section{Experimental groups}

The blank control group: DMEM medium + HSCs.

Experimental groups:

1) TGF- $\beta 1$ treatment groups: DMEM medium + HSC + TGF- $\beta 1$ (group A).

2) MSC-combined group: DMEM + HSC + TGF- $\beta 1+$ BMCs (group B).

3) Induced MSC-combined group: DMEM + HSC + TGF- $\beta 1+$ HGF-induced BMCs at 14 days (group C).

\section{Proliferation of HSCs}

HSCs were inoculated on 96-well sterile culture plates, with fusion degrees of more than $80 \%$. After synchronization, the cells were treated with medium that contained $0.4 \%$ FBS in DMEM for $24 \mathrm{~h}$, after which the media was discarded. The medium was changed to $5 \mu \mathrm{g} / \mathrm{L}$ TGF- $\beta 1$ medium for the group A. Alternatively, cells were pretreated with $5 \mu \mathrm{g} / \mathrm{L}$ TGF- $\beta 1$ for $30 \mathrm{~min}$ in the group B, which was followed by the addition of $2 \times 10^{5}$ cells $/ \mathrm{mL}$ BMCs. In the induced group C, cells were pretreated with $5 \mu \mathrm{g} / \mathrm{L}$ TGF- $\beta 1$ for $30 \mathrm{~min}$, followed by the addition of BMCs induced by HGF for 14 days. The culture medium was $2 \%$ FBS in DMEM and 6 wells were used for each group. After treatment for $44 \mathrm{~h}$, the MTT solution was added to each well and allowed to incubate for $4 \mathrm{~h}$. At this time, DMSO was added to the cells to cause lysis and the absorbance was measured with an enzyme mark tester. More specifically, the absorbance wavelength was $490 \mathrm{~nm}$, and the reference wavelength was $630 \mathrm{~nm}$.

\section{Expression of $\alpha$-SMA in HSCs}

Immunocytochemical staining was used to assess the effect of BMCs on the activation of HSCs induced by TGF- $\beta 1$. Specifically, cells were cultured on 24-well plates until they reached a confluence of more than $80 \%$. The cells were then washed twice with DMEM without serum, and treated with $0.4 \%$ FBS in DMEM for $24 \mathrm{~h}$. After treatment for $48 \mathrm{~h}, \mathrm{SABC}$ immunocytochemical staining for $\alpha$-SMA was performed, along with DAB staining. Positive staining was quantified with the help of the Beijing University of Aeronautics and Astronautics CM IAS2000-B type pathology true color picture analysis system.

\section{Expression of HSC T $\beta R I$ and T $\beta R I I$}

Expression of HSC T $\beta R I$ and T $\beta$ RII was assessed in each group by indirect immunofluorescence. Specifically, plated cells were washed twice with PBS for 5 min each time, and fixed with $4 \%$ paraformaldehyde. Then, the endogenous peroxidase activity was blocked with $0.1 \%$ TritonX-100. Fixed cells were incubated in goat serum for $30 \mathrm{~min}$ to block non-specific 
antibody-antigen interactions. After blocking, cells were incubated with a 1:100 dilution of rabbit anti-T $\beta \mathrm{RI} / \mathrm{II}$ monoclonal antibody at room temperature for $90 \mathrm{~min}$. As a negative control, PBS replaced the monoclonal antibody in the above incubation. Following the incubation, all cells were washed in PBS, and then incubated in 1:100 diluted anti-rabbit IgG-Cy3 at room temperature for $60 \mathrm{~min}$. The cells were then washed again in PBS, and observed rapidly under a fluorescent microscope. A positive signal was graded as follows: - no fluorescence; + suspicious extremely weak fluorescent; + weak fluorescence but clearly visible; + + bright fluorescent; +++ or ++++ flashing fluorescent.

The expression of HSC T $\beta$ RI and T $\beta$ RII was detected by western blotting. Specifically, cultured cells were washed in PBS and then lysed. This sample was then subjected to high speed centrifugation $\left(13,000 \mathrm{~g}, 10 \mathrm{~min}, 4^{\circ} \mathrm{C}\right)$ whereby total cell protein was collected and preserved at $-80^{\circ} \mathrm{C}$. Protein content was determined with the Bradford assay. Samples of $50 \mu \mathrm{g}$ protein/well were added to an $8 \%$ SDS gel and proteins were then separated by $8 \%$ SDS-PAGE. After electrophoresis, proteins were transferred to PVDF membranes under a current of $250 \mathrm{~mA}$ for 30-50 min. Membranes were then blocked with 5\% skim milk in PBS for $1 \mathrm{~h}$. Rabbit anti-T $\beta R I / I I$ monoclonal antibody was then added to the blot (diluted $1: 100$ ) and incubated overnight at $4{ }^{\circ} \mathrm{C}$. The blots were then washed in TBST [250 mM Tris, $1500 \mathrm{mM} \mathrm{NaCl}, 0.5 \%(\mathrm{v} / \mathrm{v})$ Tween-20] for $10 \mathrm{~min}$, after which they were incubated with secondary antibody for $90 \mathrm{~min}$ at room temperature. Chemiluminescence was used to detect the proteins. This was done with the aid of the Quantity One image analysis software. $\beta$-actin was used as an internal control and all samples were normalized to $\beta$-actin expression.

\section{Expression of $\operatorname{Smad} 2,3,4$, and 7 mRNA}

The expression of $\alpha$-SMA was detected by immunocytochemical staining after the cells in each group were cultured for $48 \mathrm{~h}$. Total cellular RNA was extracted for RT-PCR amplification with an RNA extraction and purification kit. The primers used for $\beta$-actin were 5'-GACCCAGATCATGTTTGAGACC-3', and 5'-GCAGTAATCTCCTTCTGCATCC-3'. The annealing conditions were $57^{\circ} \mathrm{C}$ for $1 \mathrm{~min}$ for 30 cycles. The amplified fragment size was 600 bp. The Smad2 primers were 5'-GCAGTAATCTCCTTCTGCATCC-3' and 5'-AAGCCATCA CCACTCAGAATTG-3', with the annealing conditions of $57^{\circ} \mathrm{C}$ for $1 \mathrm{~min}$ for 30 cycles. The amplified fragment size was $600 \mathrm{bp}$. The $\mathrm{Smad} 4$ primers were 5'-CAACACCCGCCAAGTAA TC-3' and 5'-GACCCAAACGTCACCTTCA-3', with the annealing conditions of $57^{\circ} \mathrm{C}$ for $1 \mathrm{~min}$ for 30 cycles. The amplified fragment size was $100 \mathrm{bp}$. The primers for $S m a d 3$ were 5'-GGTGTGCGGCTCTACTACATT-3' and 5'-AGTAAGGAGGAGGGGGAGACT-3' with the annealing conditions of $57^{\circ} \mathrm{C}$ for $1 \mathrm{~min}$ for 30 cycles. The primers for $\mathrm{Smad} 7$ were $5 \mathrm{p}$-GGT GCTCAAGAAACTCAAGGAG-3p and 5p-AGTAAGGAGGAGGGGGAGACT-3' with the annealing conditions of $57^{\circ} \mathrm{C}$ for 1 min for 30 cycles. The amplified fragment size was $338 \mathrm{bp}$. Products were identified by $115 \%$ agarose gel electrophoresis and analyzed by the Quantity One 41510 software. $\beta$-actin expression was used to normalize the expression of the other genes.

\section{Statistical analysis}

All data were analyzed by the SPSS 13 software package. Data are reported as means \pm standard deviation and the data were compared with the Student $t$-test. 


\section{RESULTS}

\section{Proliferation of HSCs}

Longer duration of action: group A could promote HSCs proliferation $(\mathrm{P}<0.01)$; group $\mathrm{B}$ and $\mathrm{C}$ inhibited the proliferation of HSCs, which were induced by TGF- $\beta 1(\mathrm{P}<0.05$; Table 1).

\begin{tabular}{lcc}
\multicolumn{2}{c}{ Table 1. Proliferation of HSCs in each group (means $\pm \mathrm{SD}$ ). } \\
\hline Group & $\begin{array}{c}\text { Training after 24 } \mathrm{h} \\
\text { (Absorbance) }\end{array}$ & $\begin{array}{c}\text { Training after } 48 \mathrm{~h} \\
\text { (Absorbance) }\end{array}$ \\
\hline Group A & $1.466 \pm 0.200$ & $1.438 \pm 0.185$ \\
Group B & $1.204 \pm 0.079 *$ & $1.229 \pm 0.044 *$ \\
\hline$* \mathrm{P}<0.005$ v group A &
\end{tabular}

\section{Expression of HSC $\alpha$-SMA}

After HSCs were cultured for $48 \mathrm{~h}$, the expression of $\alpha$-SMA decreased in group B and group $\mathrm{C}$ as compared with group $\mathrm{A}(\mathrm{P}<0.05$; Table 2 and Figure 1$)$.

\section{Expression of HSC T $\beta R I$ and T $\beta R I I$}

T $\beta R I$ and T $\beta$ RII protein fluorescence was clearly located in the cell membrane of the HSCs, and the expression of T $\beta R I$ and T $\beta R I I$ in each group was consistent. With respect to the HSCs activated by TGF- $\beta 1$ in group A, the fluorescence of T $\beta$ RI and T $\beta$ RII was $(+++)$, while the fluorescences of T $\beta$ RI and T $\beta$ RII in groups B and C were separately $(++)$ and $( \pm \sim+)$, respectively (Figure $2 \mathrm{~A}$ and $\mathrm{B})$.

\section{HSC T $\beta R I$ and T $\beta R I I$ protein expression}

Protein expression of T $\beta$ RI and T $\beta$ RII, as assessed by western blot, in groups B and C were significantly lower $(\mathrm{P}<0.05$ and $\mathrm{P}<0.01$, respectively), as compared to group $\mathrm{A}$ (Table 3 and Figure $3 \mathrm{~A}$ and $\mathrm{B})$.

\begin{tabular}{l} 
Table 2. Expression of HSC $\alpha$-SMA in each group. \\
\hline \begin{tabular}{lc}
\hline Group & Absorbance \\
\hline Group A & $0.102 \pm 0.013$ \\
Group B & $0.083 \pm 0.015^{*}$ \\
Group C & $0.062 \pm 0.007^{*}$ \\
\hline P $<0.05$ vs group A. Data were compared by the Student $t$-test.
\end{tabular}
\end{tabular}




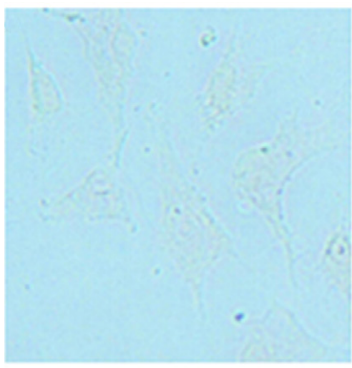

grop A

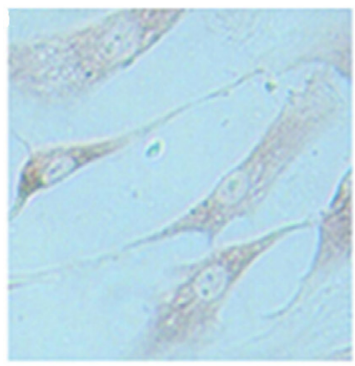

grop C

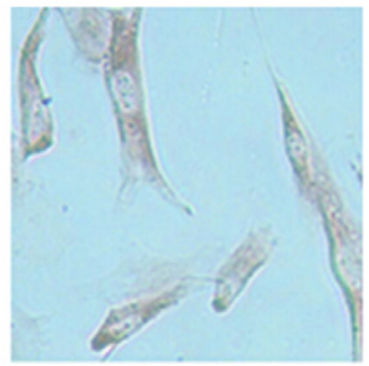

grop B

Figure 1. Expression of $\alpha$-SMA in each group after HSC stimulation. The mean absorbance value of $\alpha$-SMA of HSCs increased significantly after stimulation by TGF- $\beta 1$. HSCs stimulated by TGF- $\beta 1$ can be induced by groups B and $\mathrm{C}$. When compared with the pure group $\mathrm{A}$, the degree of staining of the cytoplasm decreased $(\mathrm{P}<0.05)$.
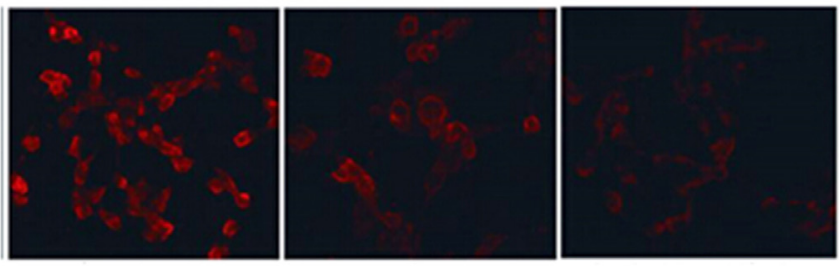

group A

group B

group C

B
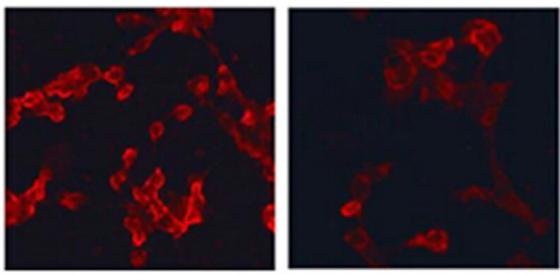

group A

group B

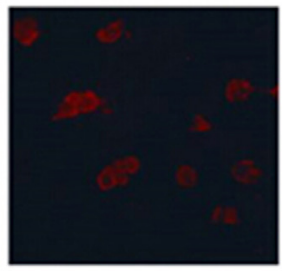

group C

Figure 2. Expression of HSCs T $\beta$ RI and T $\beta$ RII in each group. A. Expression of T $\beta$ RI in HSCs. B. Expression of T $\beta$ RII in HSCs. 
Table 3. Protein expression of HSC T $\beta R I$ and T $\beta R I I$ in each group (means $\pm S D, N=6$ ).

\begin{tabular}{lccc}
\hline Group & Group A & Group B & Group C \\
\hline T $\beta$ RI & $0.487 \pm 0.043$ & $0.362 \pm 0.028^{*}$ & $0.307 \pm 0.052^{*}$ \\
T $R$ RII & $0.403 \pm 0.071$ & $0.343 \pm 0.034^{*}$ & $0.311 \pm 0.025^{*}$ \\
\hline
\end{tabular}

$* \mathrm{P}<0.05 v s$ group A. Data were compared by the Student $t$-test.

A

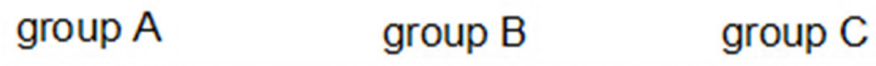

$66 \mathrm{kDa}$

$42 \mathrm{kDa}$

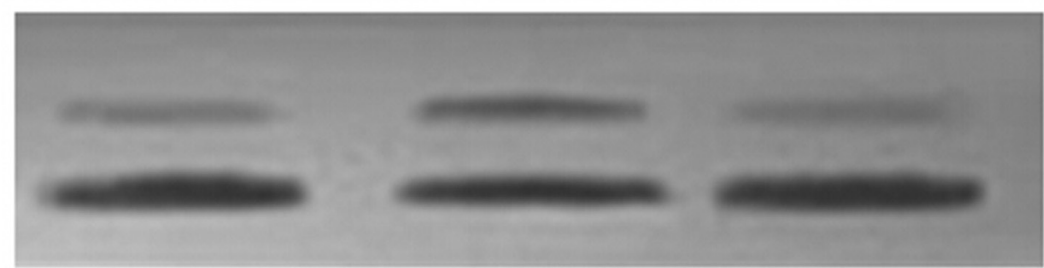

$\mathrm{B}$
group A
group B
group C

$66 \mathrm{kDa}$

$42 \mathrm{kDa}$

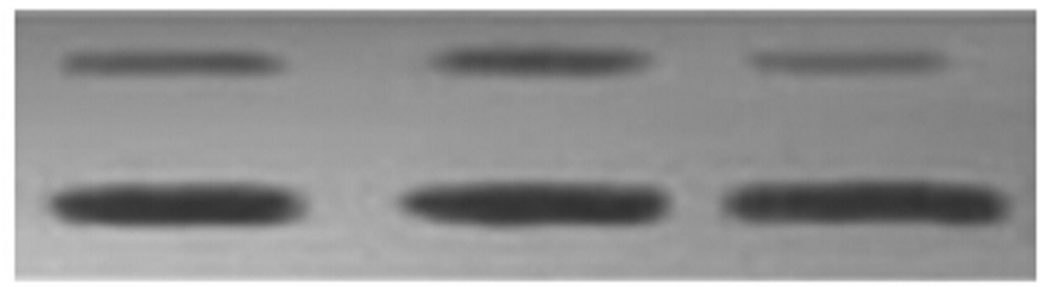

Figure 3. Protein expression of T $\beta$ RI and T $\beta R I I$ in HSCs from each group. A. Expression of T $\beta R I$ in each group: group A, MSC-combined group; group B, induced MSC-combined group; group C, TGF- $\beta 1$ treatment group. B. Expression of T $\beta$ RII in each group: group A, MSC-combined group; group B, induced MSC-combined group; group 3. TGF- $\beta 1$ treatment group.

\section{mRNA expression of Smad2/3, 4, and 7 in HSCs}

The expressions of Smad2/3, Smad4, and Smad7 mRNA for HSCs in groups B and C were suppressed $(\mathrm{P}<0.05$ and $\mathrm{P}<0.01$, respectively), as compared to the group A. Alternatively, the expression of Smad7 mRNA in HSCs was enhanced as compared to the group A (P $<0.05$; Table 4 and Figure 4).

Table 4. Expression of Smad2/3, Smad4, and Smad7 mRNA in HSCs (means \pm SD).

\begin{tabular}{llll}
\hline Group & \multicolumn{1}{c}{ Smad2/3 } & Smad4 & Smad7 \\
\hline TGF- $\beta 1$ treatment group (group A) & $0.913 \pm 0.015$ & $0.943 \pm 0.016$ & $0.818 \pm 0.016$ \\
MSC-combined group (group B) & $0.769 \pm 0.014^{*}$ & $0.866 \pm 0.014^{*}$ & $0.908 \pm 0.014 *$ \\
Induced MSC-combined group (group C) & $0.572 \pm 0.033^{*}$ & $0.601 \pm 0.034^{*}$ & $0.986 \pm 0.034^{*}$ \\
\hline
\end{tabular}

$* \mathrm{P}<0.05 v s$ group A. Data were compared by the Student $t$-test. 


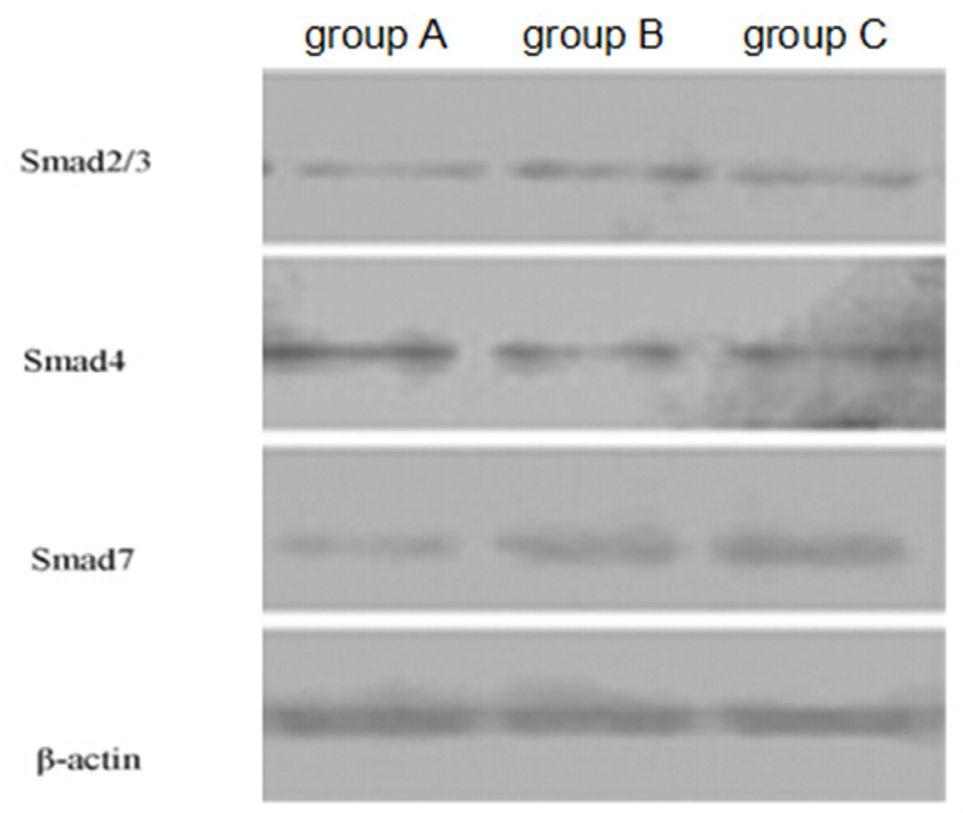

Figure 4. Expression of $\operatorname{Smad} 2 / 3, \operatorname{Smad} 4$, and $\operatorname{Smad} 7 \mathrm{mRNA}$ in HSCs. Group A = TGF- $\beta 1$ treatment group. Group $\mathrm{B}=\mathrm{MSC}$-combined group. Group $\mathrm{C}=$ induced MSC-combined group.

\section{DISCUSSION}

We selected the primary HSCs as experimental cells in this study, and the results indicate that TGF- $\beta 1$ can promote the proliferation of HSCs significantly. BMCs and induced BMCs, on the other hand, significantly inhibit the proliferation of HSCs induced by TGF- $\beta 1$, with the induced BMCs having a greater inhibitory effect. $\alpha$-SMA is a specific marker for HSCs, and our experiment proved that the expression of $\alpha$-SMA and HSC proliferation were consistent. These results suggest that the anti-hepatic fibrosis effects of BMCs may be related to its inhibition of HSC proliferation. TGF- $\beta 1$ is an important cytokine that can contribute to the development of liver fibrosis. HSCs can be transformed into MFBs when stimulated by autocrine and paracrine TGF- $\beta 1$, which may then produce a number of cytokines and ECM component, such as collagen. TGF- $\beta 1$ can also increase the expression of the TIMP protease inhibitory factor to antagonize ECM degradation and promote the progress of liver fibrosis. The activated TGF- $\beta 1$ binds to TGF- $\beta 1$ receptors on the cell membrane of HSCs, so TGF- $\beta 1$ receptors are very important. A previous study has shown that the expressions of T $\beta$ RI and T $\beta$ RII in the activated HSCs and MFBs were significantly higher than no activated HSCs and MFBs (Roberts et al., 2003). Moreover, another study found that the expression of TGF- $\beta 1$ and T $\beta R I$ in the liver increased with the development of fibrosis in chronic hepatitis $\mathrm{C}$, while T $\beta$ RII expression decreased (Roulot et al., 1999). This suggested that the expression of T $\beta R I$ and T $\beta$ RII in liver fibrosis and the variation in the T $\beta R \mathrm{R} / \mathrm{II}$ ratio might be related to the development of liver fibrosis.

Our experiment found that the expression of T $\beta R I$ and T $\beta R I I$ in the cell membrane of activated HSCs induced by TGF- $\beta 1$ increased significantly, while the expression of T $\beta$ RI and T $\beta$ RII in the cell membrane of activated HSCs induced by BMCs were suppressed. This 
suggests that BMCs can suppress the expression of T $\beta$ RI and T $\beta$ RII in the cell membrane of HSCs and antagonize the proliferation of HSCs activated by TGF- $\beta 1$. Mootsikapun et al. (2003) found that the most appropriate expression of type I collagen can appear in HSCs with the participation of Smad3. Moreover, without the formation of the Smad complex, TGF- $\beta 1$ was unable to induce HSC synthesis and secretion of collagen and other ECM components. Luo et al. (2005) found that Smad2 siRNA could effectively inhibit the expression of Smad2 in liver tissue, blocking TGF- $\beta 1$ activation of HSCs and reducing the secretion of collagen. We found that HSCs stimulated by TGF- $\beta 1$ could promote the expression of Smad $2 / 3 \mathrm{mRNA}$ in HSCs, while the BMCs can suppress the expression of Smad2/3 mRNA. This reduction can antagonize the upregulation of Smad 2 by TGF- $\beta 1$ in HSCs. Our experiment result suggested that BMCs could inhibit the expression of Smad2/3 in HSCs, antagonize the effect of TGF- $\beta 1$, and thereby exert its anti-hepatic fibrosis effects.

Dooley et al. (2003) found that the overexpression of Smad7 could inhibit the activation of HSCs, the expression of $\alpha$-SMA, and the progression of liver fibrosis. Seyhan et al. (2006) found that the Smad3 mRNA content in HSCs in the liver fibrosis model group was significantly higher than that of the normal liver group. Moreover, the expression of Smad7 mRNA decreased with the development of hepatic fibrosis. This suggests that TGF- $\beta 1$ can induce the expression of Smad 3 and activate HSCs at the same time following liver injury. Additionally, Smad7 was upregulated in an immediate negative feedback manner, which antagonized Smad 3 signal transduction within activated HSCs. This result showed that the cultured HSCs after $48 \mathrm{~h}$ were still sensitive to TGF- $\beta 1$, and when given TGF- $\beta 1$, the expression of Smad7 and Smad2/3 mRNA levels significantly increased. However, this negative feedback effect is not sufficient to inhibit TGF- $\beta 1$-induced activation of HSCs, which resulted in increased Smad2/3 mRNA. BMCs can enhance the expression of Smad7 mRNA stimulated by TGF- $\beta 1$ through a mechanism and inhibit the expression of Smad2/3 mRNA in HSCs. It was confirmed by RT-PCR.

Internal TGF- $\beta 1$ may exist in the form of latent live and its complete signal transduction process includes cell activation, across the membrane and intracellular transduction process, and so on. Although this experiment has confirmed that BMCs interfere with TGF- $\beta 1$ signaling in HSCs, the effect of BMCs on the extracellular activation and transmembrane signal of TGF- $\beta 1$ and whether these cells affect other signal molecules in HSCs remains unclear. Thus, further study is needed to clarify the mechanism by which BMCs affect TGF- $\beta 1$ signal transduction in HSCs.

\section{ACKNOWLEDGMENTS}

Research partially supported by Weifang Medical University.

\section{REFERENCES}

Brenner DA (2009). Molecular pathogenesis of liver fibrosis. Trans. Am. Clin. Climatol. Assoc. 120: 361-368.

Cassiman D, Libbrecht L, Desmet V, Denef C, et al. (2002). Hepatic stellate cell/myofibroblast subpopulations in fibrotic human and rat livers. J. Hepatol. 36: 200-209.

Dooley S, Hamzavi J, Breitkopf K, Wiercinski E, et al. (2003). Smad7 prevents activation of hepatic stellate cells and liver fibrosis in rats. Gastroenterology 125: 178-191.

Gressner OA, Rizk MS, Kovalenko E, Weiskirchen R, et al. (2008). Changing the pathogenetic roadmap of liver fibrosis? Where did it start; where will it go. J. Gastroenterol. Hepatol. 23: 1024-1035. 
Lin YL, Lin CY, Chi CW and Huang YT (2009). Study on antifibrotic effects of curcumin in rat hepatic stellate cells. Phytother. Res. 23: 927-932.

Luo HF, Wu ZY, Chen W, et al. (2005). Smad2 siRNA specificity of rat hepatic fibrosis. Shanghai Dier Yike Daxue Xuebao 25: 256-259.

Massague J, Seoane J and Wotton D (2005). Smad transcription factors. Gene Dev. 19: 2783-2810.

Mootsikapun P, Chetehotisakd P, Anunnatsiri S and Choksawadphinyo K (2003). The efficacy of fluconazole $600 \mathrm{mg}$ / day versus itraconazole $600 \mathrm{mg}$ /day as consolidation therapy of cryptoceccal meningitis in AIDs patients. J. Med. Assoc. Thai. 86: 293-298.

Parsons CJ, Takashima M and Rippe RA (2007). Molecular mechanisms of hepatic fibrogenesis. J. Gastroenterol. Hepatol. 22 (Suppl 1): S79-S84.

Roberts AB, Russo A, Felici A and Flanders KC (2003). Smad3: a key player in pathogenetic mechanisms dependent on TGF-beta. Ann. N. Y. Acad. Sci. 995: 1-10.

Roulot D, Sevosir AM, Coste T, Strosberg AD, et al. (1999). Role of transforming growth factor $\beta$ type II receptor in hepatic fibrosis: studies of human chronic hepatitis and experimental fibrosis in rats. Hepatology 29: 1730-1738.

Sarem M, Znaidak R, Macias M and Rey R (2006). Hepatic stellate cells: it's role in normal and pathological conditions. Gastroenterol. Hepatol. 29: 93-101.

Seyhan H, Hamzavi J, Wiercinska E, Gressner AM, et al. (2006). Liver fibrogenesis due to cholestasis is associated with increased Smad7 expression and Smad3 signaling. J. Cell Mol. Med. 10: 922-932. 